\title{
MECHANISMS OF INJURY TO THE CERVICAL CORD
}

\author{
By R. Braakman and L. Penning \\ Neurosurgical Department, Academisch Ziekenhuis Dykzigt, Rotterdam; Department of \\ Neuroradiology, University Hospital Groningen, the Netherlands
}

INSIGHT into the mechanism of the accidental damage to the cervical spine and spinal cord may be obtained from the evaluation of clinical and radiological data; from post-mortem investigations and from experiments, which are usually performed on animals.

Radiological signs result in various classifications of spinal injuries, for example that of Whitley and Forsyth (1960). During our meeting last year Roaf (1972) rightly criticised these classifications. The forces in two directions only are taken into account, usually. Nevertheless for clinical purposes, especially with regard to treatment, some classification is indispensable.

Table I represents our classification of radiologically recognisable lesions of the lower cervical spine with the supposed mechanism-like disruptive and compressive hyperflexion and hyperextension.

\section{TABLE I}

Supposed Mechanism in and Classification of Radiologically Recognisable Lesions of the Lower Cervical Spine
Disruptive hyperflexion
hyperflexion sprain unilateral interlocking bilateral interlocking
Compressive hyperflexion wedge compression fracture (body) tear drop fracture hyperflexion fracture luxation
Disruptive hyperextension hyperextension sprain
Compressive hyperextension hyperextension fracture luxation

\section{TABLE II}

Some 'Difficult' Lesions of the Lower Cervical Spine

No radiological signs of trauma

hyperextension sprain? traumatic disc prolapse?

Rotational forces? stenotic spinal canal?

Combined hyperflexion and hyperextension

Hyperflexion $\frac{\text { followed }}{\text { preceded }}$ by hyperextension

Table II shows some 'difficult' cases like those cord lesions without any recognisable injury on routine roentgenograms, those with rotary lesions and those with a combination of more than one mechanism. Examples of the latter are the 
combination of hyperflexion in the lower cervical, and hyperextension in the upper cervical spine and the lesions due to hyperflexion preceded or succeeded by hyperextension (Braakman \& Penning, I97I).

Four hundred cases of injuries to the lower cervical spine treated by the authors in the last decade were reviewed. Some conclusions from the comparison of the various types of injuries to the spine and the type and severity of the cord and root lesion were attempted to be drawn. The relative importance of the various factors involved were estimated in order to improve management. Although no essential new information was obtained, the results may be interesting to many of those who only see paraplegic patients and not cases without a cord lesion.

There is not a unanimous opinion about the significance of the various possible factors in the origin of traumatic neurological deficit. This results in divergent opinions regarding treatment. Theoretically the following factors may be held responsible for damage: (Table III). 'Pinching' (fig. I), that is compression from

\section{TABLE III}

Factors Responsible for Damage to the Cord in Spinal Injuries

\begin{tabular}{|c|c|}
\hline $\begin{array}{l}\text { Pinching } \\
\text { (compression from } 2 \text { sides) }\end{array}$ & $\begin{array}{l}\text { bone } \\
\text { haematoma } \\
\text { intervertebral disc } \\
\text { ligaments? }\end{array}$ \\
\hline \multicolumn{2}{|l|}{ Overstretching } \\
\hline \multicolumn{2}{|l|}{$\begin{array}{l}\text { 'Contact pressure' } \\
\text { (compression from I side) }\end{array}$} \\
\hline Traumatic oedema & \\
\hline Circulatory disturbances & \\
\hline
\end{tabular}

both sides, either by bone, haematoma, a prolapsed disc or ligaments; overstretching; 'contact-pressure' (fig. 2), that is compression from one side (Breig \& Fouad el-Nadi, I966); the development of traumatic oedema of the cord and circulatory disturbances, which may be either arterial or venous.

The significance of bony pinching is indisputable. Elementary lesions with pincing forces like bilateral interlocking and proven hyperextension sprain carry a high percentage of severe cord lesions. In Figure 3 the severity of the cord lesion in 50 cases of bilateral interlocking and in 50 cases of unilateral interlocking is compared. In unilateral interlocking, pinching in the sagittal direction is less severe (fig. 4) resulting in a shift of the diaphragm to the less severe cord lesions.

In our four cases of bilateral interlocking without neurological signs the arch was either fractured, thus prohibiting the pinching mechanism, or the natural sagittal diameter of the spinal canal was well above normal. So the impression is given that in the acute phase the pinching mechanism is more important than kinking and angulation of the cord, and the possible longitudinal overstretching.

In hyperextension fracture dislocation severe cord lesions are rare (fig. 3), due to the fact that no pinching occurs. This is because the arch usually fractures before the anterior displacement of the cranial vertebra takes place.

The significance of compression exerted by infolding ligaments is open for 
doubt and extra- or intramedullary haematomata acting as a compressive agent are rarer still.

The significance of disc prolapses is disputable. Some authors, with which we agree, state that they are rare. Schneider (I95I), on the other hand, advocated early decompressive laminectomy in order to remove any possible loose disc fragment in every patient with a severe incomplete cord lesion. Verbiest (I969) published a large series or surgically treated patients in the fournal of Bone and foint Surgery a few years ago. He reported Io prolapsed discs in 6I patients,

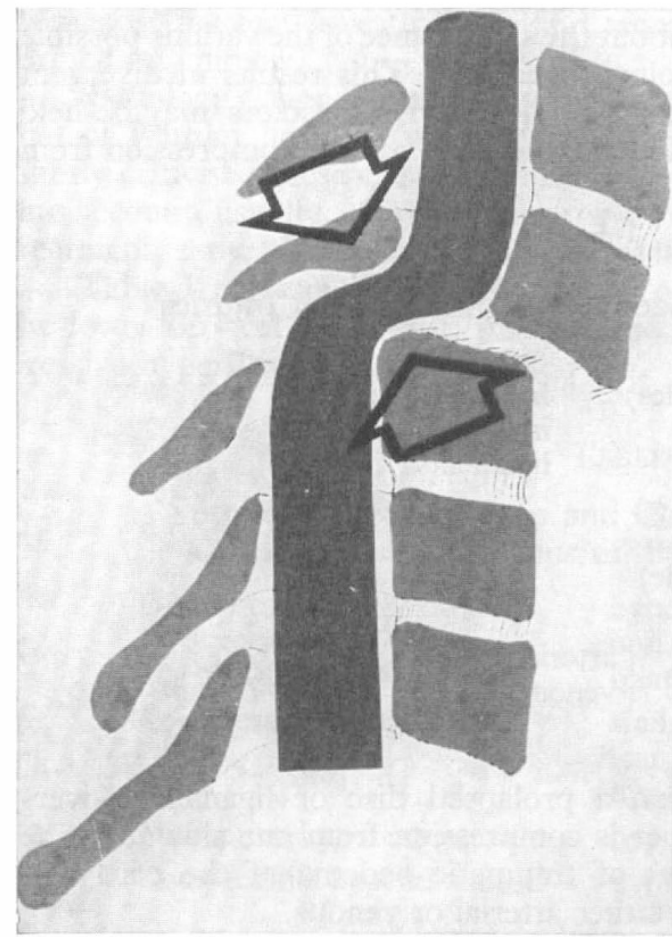

FIG. I

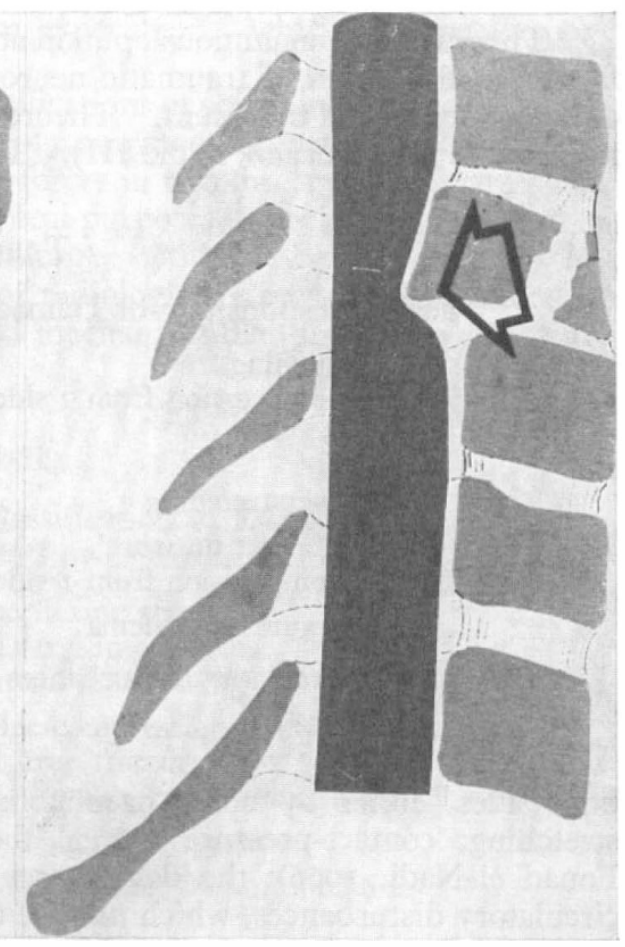

FIG. 2

'Pinching' (schematic drawing). 'Contact-pressure' (schematic drawing).

mostly hyperflexion injuries, nine at the $\mathrm{C}_{5} / 6$ level. Although he stresses the importance of the removal of the prolapse he does not demonstrate any difference in neurological recovery between cases with and without such a prolapse.

It is highly improbably that disc prolapses ever occur in hyperextension injuries. Therefore such surgical intervention for the removal of a prolapsed disc, if ever justified, is allowed only in the rare cases with compressive hyperflexion injuries showing immediate severe incomplete cord lesions not explainable by bony pinching. The patient should be under 45 years of age and the hazardous procedure only carried out by very experienced surgeons.

The significance of overstretching is difficult to estimate. It is well known that heavy skull traction may result in a progressive cord lesion (fig. 5). Generally, 
overstretching seems to be of minor importance. As to traumatic cord oedema; from experiments on animals a more surgical approach, for example, extra- or intra-medullary decompression, is promoted. This is in contrast with the current clinical opinion favouring a conservative approach. Our experience confirms that decompressive laminectomy for a supposed oedema is of no avail. Recently Ransohoff (1972) and co-workers reported a favourable influence of high doses of corticosteroids in acute traumatic cord damage in animals. This effect was not

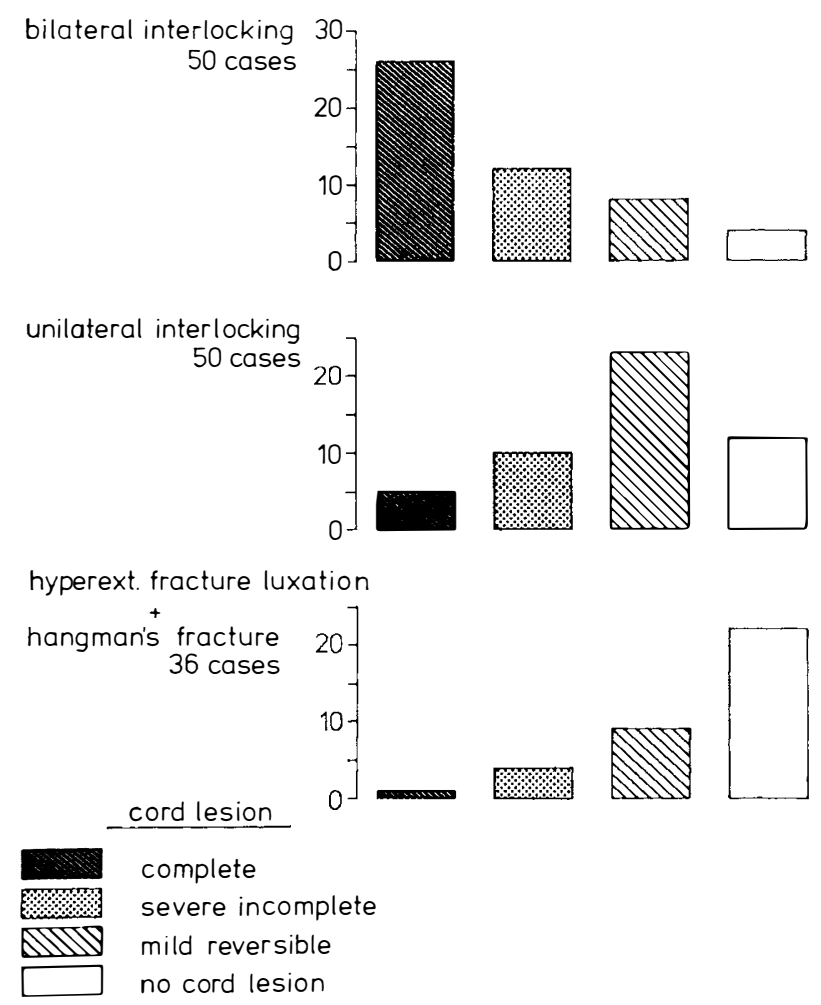

Fig. 3

Severity of cord lesions in bilateral and unilateral interlocking and in hyperextension fracture luxation.

only due to the decrease in traumatic oedema. The corticosteroids, if applied as early as possible after trauma, seemed to prevent demyelination and disintegration of the damaged cells. It remains to be seen whether Ransohoff's remarkable results will have implications for men. Nevertheless, I think that increasing numbers of recent experiments should be followed up more closely than we clinicians did in the past, especially those on the effect of corticosteroids.

The exact significance of kyphotic angulation in the acute phase of cord injury (fig. 2) resulting in contact pressure and some local stretching is not exactly known, as in most cases there is a combination with pinching. However, contact pressure is of major significance for the development of late progressive cord lesions. 
This factor is often underestimated. Verbiest (1969) has stressed the occurrence of these late progressive cord lesions in ill-reduced spine lesions especially in persistent interlocking and hyperflexion fracture-luxations. His findings are in close agreement with our experiences. In these laminectomy is usually of no avail as the contact pressure remains. Reconstructive columnotomy may, in selected cases, result in clinical neurological improvement. These results confirm the significance of contact pressure as an aetiological factor in late myelopathy. I

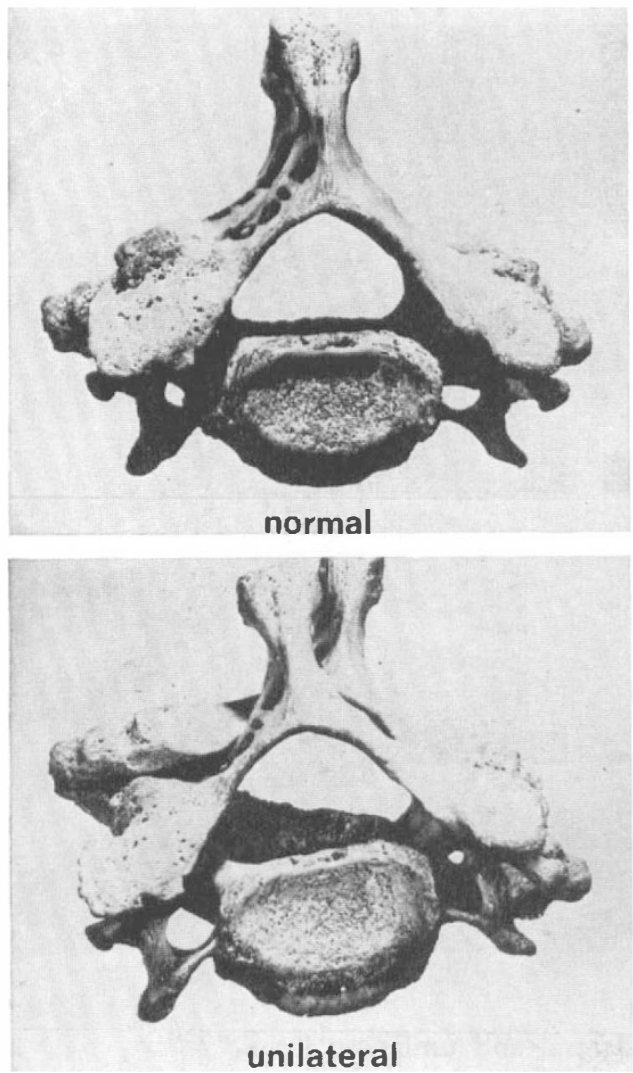

FIG. 4

Bony spinal canal seen from above at the $\mathrm{C} 5 / \mathrm{C} 6$ level in a normal situation and in unilateral and bilateral interlocking.

suppose that these cases are not admitted to paraplegic centres and are usually referred to neurosurgeons.

In their well-known important review the Stoke Mandeville group (Frankel et al. 1969) noticed progressive cord lesion in 2 per cent. of their cervical cord injuries only. Their tables do not represent the incidence of a progressive myelopathy in all cervical injuries and if misinterpreted may lead to the underestimation of the significance of optimal realignment.

The deteriorating influence of general hypoxia, e.g. due to respiratory and general circulatory disturbances, is important and well established. The significance of local arterial or venous circulatory disturbances is disputed and still 
insufficiently known. As far as therapy is concerned these local factors are, up till now, only of limited importance. However, we observed quite a few cases in which early progression of neurological signs was attributed to 'spasm', or to microvascular thrombosis, etc. In these cases the radiographs often did not disclose the lower cervical spine due to super-imposition of the shoulders. Additional radiographs revealed, for example, interlocking $\mathrm{C}_{6}-\mathrm{C}_{7}$ or $\mathrm{C}_{7}-\mathrm{Th}_{\mathrm{I}}$ as the cause for the progressive neurological involvement. One should hesitate to accept 'spasm' as an explanation and should reconsider the existence of simple mechanical

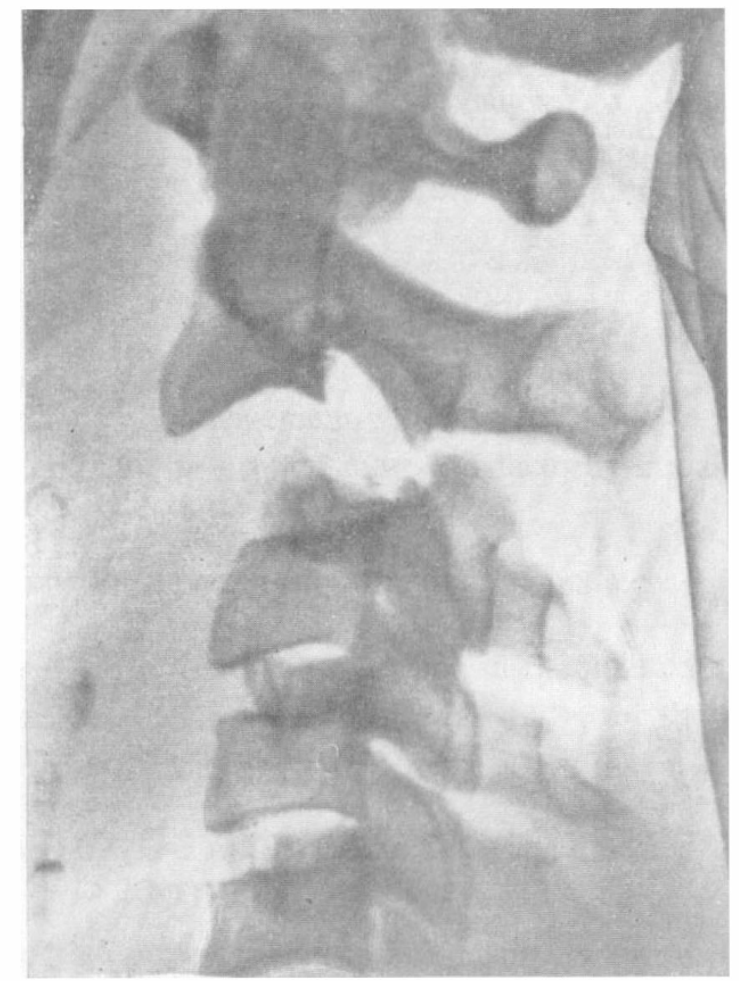

FIG. 5

Disruption in the $\mathrm{C}_{2} / \mathrm{C}_{3}$ segment due to heavy skull-traction.

factors. Radiological investigation should include the vertebra $\mathrm{C}_{7}$ and $\mathrm{ThI}$. It is interesting to note that in IOO cases of interlocking the diagnosis was missed initially in 23 , of which Io were due to insufficient radiographs of the lower cervical spine.

\section{CONCLUSION}

Bony pinching is the most important factor in acute damage. Disc prolapses are rare; haematomata rarer still. The results of experiments of the effect of corticosteroids on animals may be important for the future. The number of cases with late progressive cord signs and the significance of contact pressure in these 
cases in underestimated. In cases of cord lesions not explained by the initial roentgenogram one should reconsider mechanical factors and complete the radiography until the whole cervical spine is adequately disclosed.

\section{REFERENCES}

Braakman, R. \& Penning, L. (I97I). Injuries to the Cervical Spine. Monograph. Excerpta Medica Foundation.

BREIG, A. \& FouAd EL-NADI, A. (I966). Acta radiol. 4, 602.

Frankel, H. L., Hancock, D. O., Hyslop, G., Melzak, J., Michaelis, L. S., Ungar, G. H., Vernon, J. D. S. \& Walsh, J. J. (1969). Int. F. Paraplegia, 7, I79.

Ransohoff, J. (1972). Workshop on the Effects of Steroids on Brain Edema. Mainz.

ROAF, R. (I972). Int. F. Paraplegia, 10, 78.

SCHNEIDER, R. C. (I95I). F. Neurosurg. 8, 360.

Verbiest, H. (I969). F. Bone foint Surg. 5IA, 8, I489.

Whitley, J. F. \& Forsyth, H. F. (I960). Amer. F. Roentgenol. 83, 633. 